\title{
ARTIGO
}

do1 https://doi.org/10.22481/praxisedu.v16i41.6460

\section{A INTERLOCUÇÃO DO ESTÁGIO SUPERVISIONADO E A EDUCAÇÃO INCLUSIVA: QUE DIZEM OS TRABALHOS CIENTÍFICOS?}

\author{
THE INTERLOCUTION OF THE SUPERVISED INTERNSHIP AND INCLUSIVE \\ EDUCATION: WHAT DO SCIENTIFIC WORKS SAY?
}

\section{LA INTERLOCCION DE LAS PRACTICAS TUTELADAS Y LA EDUCACION INCLUSIVA: ¿QUÉ DICEN LOS TRABAJOS CIENTIFICOS?}

\author{
Patrícia Carla da Hora Correia \\ Universidade do Estado da Bahia - Brasil \\ Julimar Santiago Rocha \\ Universidade do Estado da Bahia - Brasil \\ Débora Regina Oliveira Santos \\ Universidade do Estado da Bahia - Brasil
}

\begin{abstract}
Resumo: A escola da contemporaneidade provocou transformações na atuação docente. A década de 80, marcada pelos movimentos sociais, e pela luta a favor da democratização do ensino, traz para o interior da escola a população que sempre esteve à margem das políticas educacionais. Torna-se imperativo uma reorganização da escola e também, dos novos docentes, ainda mais comprometidos com a transformação social, e com uma educação inclusiva. A formação inicial dos novos professores perpassa pela participação nos estágios supervisionados, entendido aqui como um momento fundamental no processo formativo. Quais são as contribuições dos trabalhos acadêmicos (2008-2018), para a produção de conhecimento na inter-relação entre estágio supervisionado e educação inclusiva? Este estudo tem como objetivo mapear e discutir as contribuições dos trabalhos acadêmico-científicos que abordem a inter-relação entre o estágio supervisionado e educação inclusiva. O método utilizado foi a pesquisa bibliográfica buscando artigos, teses e dissertações em dois repositórios acadêmicos, a saber: Associação Nacional de Pós-Graduação e Pesquisa em Educação (ANPED), e Biblioteca Digital Brasileira de Teses e Dissertações (BDTD). Mostra a sua relevância ao abordar que a formação inicial precisa contemplar no designer pedagógico das instituições superiores a partir das demandas pedagógicas, reflexão e ressignificação das práticas dos estagiários por meio de uma estrutura formativa, tendo como princípio a práxis dialógica e transformadora. Além de recomendar a realização de outras pesquisas que mostrem essa inter-relação tão necessária e urgente.
\end{abstract}

Palavras chave: Educação inclusiva. Estágio supervisionado. Formação inicial. 
Abstract: The contemporary school caused changes in teaching. The decade of the 80 s, marked by social movements, and by the struggle for the democratization of education, brings a population that has always been on the margins of educational policies to inside of the school. It was imperative to reorganize the school and also the new teachers, even more committed with social transformation and inclusive education. The initial formation of new teachers involves participation in supervised internships, presented here as a fundamental moment in the training process. The complexity of teaching linked to the proposal by an inclusive school led to the present study the investigation of following question: What are the contributions of academic studies (2008-2018), for the production of knowledge in the interrelationship between supervised internship and inclusive education? This study aims to map and discuss the contributions of academic-scientific studies that approach an interrelation between supervised internship and inclusive education. The method used was a bibliographic research searching for articles, theses and dissertations in two academic repositories, to know: National Association of Postgraduate Studies and Research in Education (ANPED), and Brazilian Digital Library of Theses and Dissertations (BDTD). It shows your relevance when approaching that the initial formation needs to contemplate in the pedagogical designer of the colleges from the pedagogical demands, reflection and reframing of the interns' practices through a formative structure, having as principle a dialogical and transforming praxis. In addition to recommending further research that shows this much needed and urgent interrelationship.

Keywords: Inclusive education. Supervised internship. Initial formation.

Resumen: La escuela de la contemporaneidad provocó transformaciones en la actuación docente. La década de 80, marcada por los movimientos sociales y por la lucha en favor de la democratización del enseno, trae para el interior de la escuela la populación que siempre estuvo a margen de las políticas educacionales. Se hace imperativa una reorganización de la escuela y también de los nuevos docentes, aun más comprometidos con la transformación social y con una educación inclusiva. La formación inicial de los nuevos profesores pasa por la participación en las prácticas tuteladas, entendidas aquí como un momento fundamental en el proceso formativo. ¿Cuáles son las contribuciones de los trabajos académicos (2008-2018), para la producción del conocimiento en la inter relación entre prácticas tuteladas y la educación inclusiva? Este estudio tiene como objetivo mapear y discutir contribuciones de los trabajos académicos-científicos que aborden la interrelación entre la práctica tutelada y la educación inclusiva. El método utilizado fue la pesquisa bibliográfica, buscando artículos, tesis y disertaciones en dos repositorios académicos a saber: Asociación Nacional de Pos-Graduación y Pesquisa en Educación (ANPED), y la Biblioteca Digital Brasileña de Tesis y Disertaciones (BDTD). Muestra a su relevancia al abordar que la formación inicial necesita contemplar en el programa pedagógico de las instituciones superiores, a partir de las demandas pedagógicas, reflexión y resignificación de las actividades de los profesores en formación por medio de una estructura formativa teniendo como principio la praxis dialógica y transformadora. Además de recomendar la realización de otras investigaciones que muestren esta interrelación tan necesaria y urgente.

Palabras clave: Educación inclusiva. Prácticas tuteladas. Formación inicial.

\section{Introdução}

A escola na atualidade se apresenta plural, com novos paradigmas de comunicação, transformada por questões sociais, éticas, políticas e filosóficas, e se abre para atender a heterogeneidade proposta pela inclusão. A escola nesse novo tempo torna a tarefa docente ainda mais complexa. Os 
desafios propostos pelo ambiente escolar e pela sociedade convocam o professor a reflexões acerca de seu trabalho, suas práticas em sala de aula, sua visão de homem, mundo e sociedade.

O cenário contemporâneo da atuação docente provocou modificações em seu papel, uma vez que a escola hoje preocupa-se não apenas com a transmissão de conhecimentos, mas também contribui para o desenvolvimento da subjetividade dos educandos, atuando no processo de humanização. O trabalho do professor não é apenas técnico, mas sim de formação, o que implica em posturas onde não cabe a neutralidade. Discussões sobre os currículos dos cursos de licenciatura emergem a todo momento, questiona-se então: Estariam as instituições de Ensino Superior formando professores para o desenvolvimento de uma práxis voltada para a inclusão de todos os sujeitos? O olhar do novo docente é ampliado para enxergar a educação como uma prática democrática e inclusiva?

A escrita desse artigo se configura como um marco reflexivo na vida de três educadoras que participam ativamente tanto da Educação Básica como da Educação Superior. Um momento para analisar as inquietações que alunos/docentes/estagiários trazem para trocas significativas quando chega o momento de enfrentar uma sala de aula. Em ocasiões diversas, seja orientando estágios supervisionados, recebendo estagiários em nossas unidades escolares ou como o professor-docente que age como um mentor do novo profissional da educação, somos surpreendidos com questionamentos acerca da inclusão dos alunos. Inquietações referentes à diversidade dos sujeitos/alunos que compõem a escola da contemporaneidade.

Esse olhar do "novo docente" incentivou a realização de um mapeamento de trabalhos acadêmico-científicos questionando o embasamento teórico e prático para que o mesmo possa desenvolver a sua prática educativa de forma a atender atual política de educação especial brasileira, em sua perspectiva inclusiva. Esse trabalho busca, portanto, fazer o levantamento de trabalhos acadêmicos, pesquisas na área de educação que tragam aportes para o estágio supervisionado, através da seguinte questão norteadora: Quais são as contribuições dos trabalhos acadêmicos (2008-2018), para a produção de conhecimento na inter-relação entre estágio supervisionado e Educação inclusiva?

A pesquisa traz como objetivo geral: Refletir sobre as contribuições dos trabalhos acadêmicos (2008-2018), para a produção de conhecimento na inter-relação entre estágio supervisionado e Educação inclusiva. Os objetivos específicos traçados foram: Identificar pesquisas construídas no período de 2008 a 2018; descrever o caminho percorrido por cada pesquisador; analisar as contribuições relacionadas a estágio supervisionado e Educação inclusiva. Assim, o trabalho passou por etapas, as quais serão mencionadas a seguir.

Primeiramente escolhemos analisar trabalhos da Associação Nacional de Pós-Graduação e Pesquisa em Educação (ANPED), por considerar a sua relevância para o desenvolvimento da ciência, da educação e da cultura; o incentivo a pesquisa educacional e os temas a ela relacionados, bem como sua atuação nas principais lutas pela universalização e desenvolvimento da educação no Brasil. 
Partimos então para uma análise preliminar dos trabalhos apresentados na ANPED nos últimos dez anos (2008-2018) com o objetivo de refletir sobre as contribuições destes para a produção de conhecimento na inter-relação entre estágio supervisionado e Educação inclusiva. Elegemos para essa análise dois grupos de trabalho: O Grupo de Trabalho de Educação Especial (GT15) e o de Formação de Professores (GT8).

Não satisfeitas com os dados obtidos elegemos o site da Biblioteca Digital Brasileira de Teses e Dissertações (BDTD), esse encontrado no endereço http://bdtd.ibict.br/vufind/ para o levantamento de teses e dissertações que discutissem as duas temáticas pesquisadas. Esse site integra e dissemina textos completos das teses e dissertações defendidas nas instituições brasileiras de ensino superior e pesquisa. Sua utilização propicia maior visibilidade da produção científica nacional e a difusão de informações de interesse científico e tecnológico para a sociedade em geral.

A análise de pesquisas recentes tendo como temáticas a Educação Inclusiva e o estágio supervisionado, levanta a possibilidade de mapear e conhecer como os diferentes teóricos e pesquisadores têm tratado o tema em questão, o que vem sendo privilegiado em determinado período histórico em detrimento de outros.

\section{Trajetória Metodológica}

Este estudo caracteriza-se como uma pesquisa bibliográfica com o objetivo de mapear e discutir as contribuições dos trabalhos acadêmico-científicos que abordem a inter-relação entre o estágio supervisionado e educação inclusiva. Para a realização desse levantamento foi realizada uma busca em dois repositórios, o primeiro na Associação Nacional de Pós-Graduação e Pesquisa em Educação (ANPED), e o segundo no site da Biblioteca Digital Brasileira de Teses e Dissertações (BDTD).

As pesquisas de cunho bibliográfico buscam o desvelamento do que já foi construído apontando caminhos para novas produções, além de contribuir para a sistematização das produções em determinado período. Soares (1989) ressalta que:

Essa compreensão do estado de conhecimento sobre um tema, em determinado momento, é necessária no processo de evolução da ciência, afim de que se ordene periodicamente o conjunto de informações e resultados já obtidos, ordenação que permita indicação das possibilidades de integração de diferentes perspectivas, aparentemente autônomas, a identificação de duplicações ou contradições, e a determinação de lacunas e vieses. (SOARES, 1989, p. 3)

Entendemos que a produção e acesso a pesquisas bibliográficas além de ser objeto de estudo e reflexão sobre a evolução científica, emerge também como meio de preservação da memória e disseminação democratizada do conhecimento científico. 
Iniciamos o mapeamento nos trabalhos apresentados nas reuniões de divulgação científica da Associação Nacional de Pesquisas em Educação (ANPED). Dentro da ANPED, selecionamos dois grupos de trabalho que discutem as temáticas centrais de nossa proposta - o grupo de trabalho da Educação Especial: GT15; e o grupo de trabalho da formação de professores: GT 08. O recorte temporal definido inclui o levantamento das pesquisas apresentadas e publicadas na ANPED entre 2008 e 2018. Definimos esse recorte temporal em função de completar uma década da publicação da Política Nacional da Educação Especial na perspectiva da Educação Inclusiva (BRASIL, 2008).

Durante este levantamento foram selecionadas as pesquisas que apresentaram os descritores: educação especial, educação inclusiva e estágio supervisionado em seus títulos, resumos ou palavras-chave. Devido ao quantitativo mínimo de pesquisas encontradas foi necessário acrescentar o descritor, formação inicial, identificando trabalhos que ao falarem da formação inicial dos professores também discutiam a prática inicial dos docentes associada à educação inclusiva. André (2009) verificou que o interesse pelo tema formação inicial tem diminuído ao longo dos anos, e se acrescentarmos a isso a relação com a educação especial a carência fica ainda maior.

Ao mesmo tempo em que cresce o número de pesquisas voltadas para o professor, diminui o número de investigações sobre a formação inicial, o que causa preocupação. Ainda carecemos de muitos conhecimentos sobre as metas, os conteúdos e as estratégias mais efetivas para formar professores. Pouco sabemos sobre qual a organização curricular mais adequada, quais as práticas de ensino mais eficazes e que forma de gestão propiciam uma formação de qualidade. Por isso temos de continuar nossas pesquisas sobre formação inicial. (ANDRÉ, 2009, p. 51-52).

O Grupo de Trabalho da Formação de professores (GT 08) tem como objetivo principal o estudo do processo de construção, desenvolvimento e aprofundamento do conhecimento e das competências necessárias ao exercício da profissão de ensinar, seus impactos e resultados. O ponto de partida para a sua criação foi o final da década de 1970 início dos anos 1980, “[...]momento histórico em que os movimentos sociais se constituíram de forma mais vigorosa e alcançaram legitimidade para abrir novos canais de debates [...] (BRZEZINSKI, 2007, p. 2).” Os educadores resistiram ao modelo imposto de formação docente e após várias mobilizações, em 1984, o GT Licenciaturas foi constituído sob a coordenação da professora Míriam Krasilchik, com seus membros se reunindo pela primeira vez na $7^{\text {a }}$ Reunião Anual da ANPED, em Brasília, 1984; sendo modificado posteriormente a sua denominação, que passou a ser chamado de "Formação de Professores". 
Já o Grupo de Trabalho da Educação Especial (GT15) foi criado em 1991, dez anos após os primeiros GTs da ANPED. O GT 15 foi instituído após funcionar dois anos como Grupo de Estudos, coordenado pela profa. Elcie Masini, da Universidade de São Paulo (USP) (FERREIRA; BUENO, 2011), formado por pesquisadores e professores ligados à Educação Especial que já se debruçavam em discutir lacunas para a referida área:

Já ali, o grupo compartilhava a visão da carência de uma atuação profissional mais adequada e comprometida com o trabalho educacional "especial", ao registrar o predomínio do assistencialismo, a escassez de profissionais, a necessidade de tentar conferir à educação do portador de deficiência um caminho possível para a integração social. (FERREIRA; BUENO, 2011, p.145)

Em nossa busca encontramos três trabalhos do GT08 e um do GT 15, (sendo quatro trabalhos no total), o que nos indica que a discussão acerca da formação de professores precisa avançar ainda mais visando à ampliação da prática docente para todos os sujeitos, bem como a visão mais aguçada acerca dessa prática com subsídios da educação especial na perspectiva inclusiva.

Passamos então a investigar trabalhos em um segundo repositório: a Biblioteca Digital Brasileira de Teses e Dissertações (BDTD). Criada no ano de 2003, “[...]é pioneira no Brasil com a filosofia do Acesso Aberto e sua implantação foi uma iniciativa do Instituto Brasileiro de Informação em Ciência e Tecnologia (IBICT) (BRUMATI, 2015, p. 68). " Trata-se de uma reunião em uma única fonte das informações bibliográficas das teses e dissertações das instituições educacionais brasileiras, permitindo a localização e disponibilização das publicações eletrônicas desse tipo de acervo.

Para a definição do corpus de análise, foram selecionados os resumos que continham a associação em pares das mesmas palavras utilizadas na busca na ANPED: educação especial, educação inclusiva e estágio supervisionado. A busca na BDTD nos levou a cinco trabalhos: duas teses e três dissertações. A seguir abordaremos acerca dos achados de cada um dos nove trabalhos encontrados nos dois repositórios, sistematizados no Quadro 1.

Quadro 1 - Identificação dos trabalhos científicos pesquisados

\begin{tabular}{|c|l|c|}
\hline REPOSITÓRIO & \multicolumn{1}{|c|}{ TRABALHOS } & CARACTERIZAÇÃO \\
\hline \multirow{5}{*}{ A } & $\begin{array}{l}\text { AGAPITO, Juliano; RIBEIRO, Sonia Maria. A formação inicial de } \\
\text { professores em interlocução com a perspectiva educacional } \\
\text { inclusiva. Disponível em: } \\
\text { http://www.anped.org.br/sites/default/files/trabalho-gt08-4110.pdf }\end{array}$ & Artigo \\
\cline { 2 - 4 } & $\begin{array}{l}\text { BRABO, Gabriela Maria Barbosa. A formação docente inicial na } 08 \\
\text { perspectiva da educação inclusiva: com a palavra, o professor }\end{array}$ & \multicolumn{1}{c|}{ Artigo } \\
GT 15
\end{tabular}




\begin{tabular}{|c|c|c|}
\hline \multirow{3}{*}{$\begin{array}{l}\mathbf{N} \\
\mathbf{P} \\
\mathbf{E} \\
\mathbf{D}\end{array}$} & 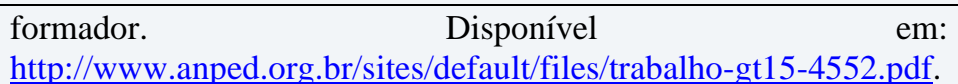 & \\
\hline & $\begin{array}{l}\text { BRAGA, Denise Rodinski. Formação inicial de professores e } \\
\text { educação especial. Disponível em: } \\
\text { http://www.anped.org.br/sites/default/files/gt08-5205-int.pdf. }\end{array}$ & $\begin{array}{l}\text { Artigo } \\
\text { GT } 08\end{array}$ \\
\hline & $\begin{array}{l}\text { KAUSS, Clarissa Teixeira; REIS, Haydéa Maria Marino de } \\
\text { Sant'Anna. O profissional professor e a educação inclusiva: } \\
\text { representações sociais em construção. REUNIÃO ANUAL DA } \\
\text { ANPED, 36. Caxambu 2013. Anais 2013. Disponível em: } \\
\text { http://www.anped.org.br/sites/default/files/gt08_2785 texto.pdf. }\end{array}$ & $\begin{array}{l}\text { Artigo } \\
\text { GT } 08\end{array}$ \\
\hline \multirow{5}{*}{$\begin{array}{c}\mathbf{B} \\
\mathbf{D} \\
\mathbf{T} \\
\mathbf{D}\end{array}$} & $\begin{array}{l}\text { ALMEIDA, Luiz Fernando Garcia de. Formação inicial do } \\
\text { professor de Educação Física para o trabalho com alunos com } \\
\text { necessidades educacionais especiais, 2018. Disponível em } \\
<\text { http://bdtd.ibict.br/vufind/Record/UNIOESTE- } \\
\text { 1_90efa74e54ea139b355a3838ea57e73c> }\end{array}$ & $\begin{array}{c}\text { Dissertação de Mestrado } \\
\text { UNIOESTE }\end{array}$ \\
\hline & $\begin{array}{l}\text { BASSO, Sabrina Pereira Soares. Cursos de Licenciatura na área de } \\
\text { Ciências: A temática inclusão escolar de alunos com necessidades } \\
\text { educacionais especiais, } 2015 . \quad \text { Disponível em } \\
\text { <http://bdtd.ibict.br/vufind/Record/UNSP } \\
\text { 393459a79a88fe5327e7d4 } \\
\end{array}$ & $\begin{array}{l}\text { Tese } \\
\text { Universidade Estadual } \\
\text { Paulista }\end{array}$ \\
\hline & $\begin{array}{l}\text { FIELD'S, Karla Amâncio Pinto. Saberes profissionais para o } \\
\text { exercício da docência em Química voltado à Educação Inclusiva. } \\
\text { 2014. } \\
\text { hisponível } \\
\text { (ttp://bdtd.ibict.br/vufind/Record/UFG_0ff9938e46ae61fb02e0fd8 } \\
\text { 0ad84c2f9> }\end{array}$ & $\begin{array}{l}\text { Tese. } \\
\text { Universidade Federal de } \\
\text { Goiás }\end{array}$ \\
\hline & $\begin{array}{l}\text { ROSA, Denise Ferreira da. Produção do sujeito deficiente no } \\
\text { contorno das políticas de educação inclusiva e da formação de } \\
\text { professores em educação especial. 2016. Disponível em } \\
\text { <https://repositorio.ufsm.br/handle/1/7278> Acesso em: } 10 \text { set. } \\
2019\end{array}$ & $\begin{array}{l}\text { Dissertação de Mestrado } \\
\text { Universidade Federal de } \\
\text { Santa Maria }\end{array}$ \\
\hline & $\begin{array}{l}\text { SOUSA, Manoel Pinéo de. O estágio curricular supervisionado nos } \\
\text { cursos de licenciatura em tempos de inclusão. (Dissertação de } \\
\text { Mestrado). Fortaleza: Universidade Estadual do Ceará, } 2017 . \\
\text { Disponível em } \quad \text { <http://bdtd.ibict.br/vufind/Record/UECE- } \\
\text { 0_1cef27c85a12946929b1f1bb6b2024028> }\end{array}$ & $\begin{array}{l}\text { Dissertação de } \\
\text { Mestrado) Universidade } \\
\text { Estadual do Ceará }\end{array}$ \\
\hline
\end{tabular}

Fonte: Elaborado pelas pesquisadoras a partir da análise dos dados da pesquisa.

\section{O Estágio Supervisionado, formação inicial docente}

É desafiador refletir sobre a formação de professores no Brasil uma vez que os novos discursos que permeiam os cursos nas universidades apontam que "a profissão docente encontra-se sob a tensão de dois processos antagônicos: a profissionalização e a proletarização (BONFANTE, BETT, BITTENCOURT, 2018, p. 80)”. A desvalorização do trabalho docente, associada à compreensão do professor como mero técnico que executa tarefas, afeta negativamente a formação dos novos docentes, bem como tem esvaziado as licenciaturas ao longo dos anos.

A formação inicial dos docentes perpassa pela participação nos estágios supervisionados. Entendemos que este é um momento fundamental no processo formativo. Sua discussão, entretanto, nos revela a velha dicotomia entre teoria e prática. Freire (2000, p. 24) aponta que é necessária uma análise crítica e aprofundada sobre a prática, pois do contrário “a 
teoria vira blábláblá e a prática, ativismo". A importância desse momento da formação inicial é refletida na fala de Marques; Garrido (2015):

Cabe à formação inicial, portanto, possibilitar ao futuro docente a apropriação
de saberes relacionados ao conhecimento específico a ser ensinado e às formas
de ensiná-lo; não basta que os licenciandos saibam o conteúdo; é preciso que
conheçam como o aluno aprende, de que maneira organizar situações de
aprendizagem, como avaliar; é preciso que saibam também o porquê de
ensinar determinado conteúdo, qual a relação de sua disciplina com as demais,
qual a contribuição desse conteúdo para a formação do aluno, qual projeto
formativo orienta sua ação. Cabe, ainda, à formação acadêmica inicial
promover a reflexão a partir dos saberes provenientes da experiência, como
aluno, dos futuros docentes, ressignificando-as à luz dos saberes da
Pedagogia. (MARQUES; GARRIDO, 2015, p. 146).

Uma formação que possibilite a reflexão, que propicie a autonomia na tomada de decisões, que oportunize momentos e trocas para análise de sua prática. Que não seja apenas o cumprimento de horas para a conclusão do curso, mas uma parte da sua formação que se seguirá durante todo o exercício da docência. Cabe analisar também o aporte legal desse momento da formação que é o estágio supervisionado.

Andrade; Resende (2010), ao discutirem os marcos regulatórios do estágio no Brasil, apontam que anterior a Lei de Diretrizes Bases da Educação Nacional (LDB) a formação de professores no Brasil não tinha um cunho intelectual, além disso, a prática era colocada em segundo plano e longe da real situação das salas de aulas. O Estágio Supervisionado surge, pela primeira vez, como componente mínimo curricular obrigatório, no Parecer do Conselho Federal de Educação 292, de 14 de novembro de 1962, devendo ser cumprido por todos os cursos de formação de professores da época. Andrade; Resende (2010) apontam ainda que:

[...] o estágio devesse ocorrer nas escolas da rede de ensino. Nesse espaço, o futuro professor seria assistido por educadores especialmente designados para orientá-lo, trazendo para a discussão os êxitos e erros cometidos pelo aluno estagiário. Definia, ainda, que o estágio tivesse um período de duração de um semestre letivo. Ao realizar o estágio, em escolas da rede de ensino, os futuros professores teriam a oportunidade de "aplicar" os conhecimentos adquiridos ao longo do seu curso, dentro das possibilidades e limitações de uma escola "real" (ANDRADE; RESENDE, p. 236, 2010)

A década de 80 , marcada pela efusão dos movimentos sociais, e pela luta a favor da democratização do ensino, traz para o interior da escola a população que sempre esteve à margem das políticas educacionais. Os movimentos sociais, antes silenciados pelo autoritarismo, ressurgiram como forças políticas. Vários setores da sociedade gritaram 
reivindicando seus direitos: negros, mulheres, índios, trabalhadores, sem-teto, sem-terra e, também, as pessoas com deficiência. Toda essa conjuntura exige uma reorganização da escola e também, dos novos docentes, agora ainda mais comprometidos com a transformação social, e com uma educação inclusiva.

A Lei $N^{\circ}$. 9.394/96 trouxe mudanças estruturais importantes, entre elas, a abertura para a educação especial. Mas também, aborda que a formação dos profissionais da educação deve incluir teoria e prática. Em 2002, foi aprovada a Resolução CNE/CP nº. 1/2002, que estabeleceu as Diretrizes Curriculares Nacionais para a Formação de Professores da Educação Básica, em nível superior, curso de licenciatura, de graduação plena. A referida resolução determina que a formação de professores para atuar nas diferentes etapas e modalidades da educação básica deve observar três princípios norteadores, entre eles, garantir a coerência entre a formação oferecida e a prática esperada do futuro professor.

Ressaltamos também a promulgação da Lei $\mathrm{N}^{\circ} 11.788$, de 25 de setembro de 2008, que dispõe sobre o estágio de estudantes. Ainda que não restrito à formação de professores, apresenta a seguinte definição de estágio:

Art. 1o Estágio é ato educativo escolar supervisionado, desenvolvido no ambiente de trabalho, que visa à preparação para o trabalho produtivo de educandos que estejam frequentando o ensino regular em instituições de educação superior, de educação profissional, de ensino médio, da educação especial e dos anos finais do ensino fundamental, na modalidade profissional da educação de jovens e adultos. (BRASIL 2008).

Com base nesse entendimento, e aplicando à formação de professores, primeiro é preciso destacar o caráter educativo e formativo do estágio, o que torna cada profissional em exercício nas escolas, um mentor para esse novo docente, que independente da fase da vida que esteja vivendo, precisará de auxílio para planejar, executar e avaliar as suas ações no interior da escola. Segundo Scalabrin; Molinari (2013, p. 3): “[...] o professor regente deve ter consciência da importância do trabalho coletivo, de trocar experiências, de auxiliar o estagiário na sua formação, pois um aprende com o outro num sistema de cooperação.”

Outro fator relevante é que se trata de uma ação supervisionada. Essa ação cabe ao professor orientador da instituição de ensino que o estagiário está vinculado, e também a um supervisor da parte concedente. Enquanto o primeiro é remunerado para essa ação, o segundo, não recebe nenhum valor, exceto àqueles ligados ao Programa Institucional de Bolsa de Iniciação à Docência - PIBID. A seguir trazemos os achados das pesquisas acerca do estágio supervisionado. 


\section{O que dizem os trabalhos científicos?}

Após o levantamento dos trabalhos partimos para a análise com o objetivo de conhecer o que já foi construído, descrever o caminho que cada pesquisador trilhou ao discutir as temáticas que elegemos, promovendo assim uma reflexão acerca das contribuições dos trabalhos acadêmicos produzidos no período de 2008-2018, para a produção de conhecimento na inter-relação entre estágio supervisionado e Educação Inclusiva. Cabe ressaltar que as pesquisas de caráter bibliográfico:

Também são reconhecidas por realizarem uma metodologia de caráter inventariante e descritivo da produção acadêmica e científica sobre o tema que busca investigar, à luz de categorias e facetas que se caracterizam enquanto tais em cada trabalho e no conjunto deles, sob os quais o fenômeno passa a ser analisado. (FERREIRA, 2002 p. 258)

Primeiramente vamos descrever o objetivo principal e sujeitos da investigação de cada pesquisa, em seguida, como eles concebem o Estágio Supervisionado e, depois uma reflexão acerca da Educação Inclusiva. Os trabalhos mapeados na ANPED trazem reflexão sobre a formação inicial dos professores nos cursos de licenciatura com destaque para o Curso de Pedagogia, ora tendo como sujeitos das pesquisas os alunos, ora o professor-formador dos "novos docentes".

Braga (2009) traz em sua pesquisa o levantamento de documentos nacionais e internacionais relacionados à formação inicial de professores em relação à Educação Especial nas classes do Ensino Regular e a realização de trabalho de campo numa Universidade pública gratuita, em curso de Pedagogia, Estado do Paraná com alunos do último ano do curso.

O trabalho de Brabo (2015) teve como campo de pesquisa a Universidade Federal do Rio Grande do Sul (UFRGS); os sujeitos foram os professores da única disciplina generalista dessa formação - Intervenção Pedagógica e Necessidades Educativas Especiais. A pesquisa que serviu de base para a tese de doutorado da autora (2008-2013), teve como ponto de partida a seguinte frase: "Não fui preparado para ensinar esse aluno". Aborda a reestruturação curricular nas licenciaturas: "para que os futuros professores da educação básica possam sair minimamente, se não preparados, pelo menos familiarizados com os conceitos referentes à Educação Especial e sensibilizados pelos princípios que norteiam a Educação Inclusiva (BRABO, 2015, p. 2). 
Agapito; Ribeiro (2015) apresentam a produção com o intuito de realizar uma aproximação entre as peculiaridades da formação inicial de professores e a perspectiva educacional inclusiva, que prevê sistemas educativos que atendam com qualidade aos diferentes sujeitos que compõem nossa sociedade. A investigação foi realizada com acadêmicos do último ano/semestre de sete cursos de licenciatura de uma universidade do estado de Santa Catarina.

Fruto de uma dissertação de Mestrado em Letras e Ciências Humanas na área interdisciplinar surge a pesquisa de Kauss; Reis (2013), realizada no espaço acadêmicocientífico do Curso de Pedagogia de uma Universidade da Baixada Fluminense no estado do Rio de Janeiro. Os sujeitos foram graduandos de Pedagogia, em especial alunos do $3^{\circ}$ e do $6^{\circ}$ períodos. A investigação foi ancorada nos seguintes questionamentos: Quais são as representações sociais com que os estudantes de Pedagogia estão entendendo o paradigma inclusivo de educação? Quais são os valores que permeiam as racionalidades materializadas em seus discursos?

Enquanto os trabalhos acima tiveram como foco principal os alunos dos cursos de Pedagogia, as produções encontradas no BDTD apresentam pesquisas em diferentes cursos de licenciatura: Basso (2015) se debruçou em analisar a formação inicial dos professores da área de Ciências (Biologia, Física e Química), voltada para a Educação Inclusiva/Educação Especial, nos cursos de licenciatura das universidades públicas estaduais do estado de São Paulo. Para isso, aplicou questionário aos alunos do último ano dos cursos de Licenciatura em Ciências, aos docentes que lecionam disciplinas que abordam a temática da Educação Inclusiva e aos docentes responsáveis pela disciplina de Estágio Supervisionado.

Field's (2014) investigou a construção e mobilização dos saberes docentes para a formação de professores de Química para a inclusão escolar. Seu procedimento metodológico foi a pesquisa-ação desenvolvida em duas etapas: A primeira contemplou o planejamento e desenvolvimento da disciplina de núcleo livre intitulada Fundamentos de Educação Inclusiva (FEI) em 2010 e o segundo ciclo foi o desenvolvimento de estágios supervisionados no Centro Brasileiro de Reabilitação e Apoio ao Deficiente Visual (CEBRAV) em 2011.

Verificar como ocorre a formação inicial dos professores de Educação Física para o trabalho com alunos com necessidades educacionais especiais, inseridos nas escolas regulares foi o enfoque da pesquisa desenvolvida por Almeida (2018). O lócus de seu trabalho foram três cursos de licenciatura em Educação Física de Instituições de Ensino Superior públicas e privadas do Oeste do Paraná. 
O material de pesquisa de Rosa (2016) foram os relatórios de Estágio Supervisionado/Déficit Cognitivo do Curso de Educação Especial Licenciatura Plena Diurno/CE da Universidade Federal de Santa Maria (UFSM), escritos pelos acadêmicos em formação, no final do Curso, considerando o atravessamento da Política Nacional de Educação Especial na Perspectiva Inclusiva.

A investigação de Sousa (2017) teve como objetivo geral analisar os limites e possibilidades do Estágio Supervisionado no processo de formação docente, enfatizando as necessidades dos alunos com deficiência nos cursos de licenciatura da Universidade Estadual do Ceará, na cidade de Fortaleza. Os sujeitos participantes foram os professores da universidade responsáveis pela disciplina de Estágio.

Antes de analisarmos a concepção que os pesquisadores trazem acerca do estágio supervisionado cabe a reflexão sobre esse momento tão importante na vida do licenciado. Momento esse que o faz pisar no chão da escola, e geralmente é a escola pública que se abre a essa demanda, e vivenciar ali todas as facetas da educação em nosso país. O estágio é o momento de construção e reafirmação da profissão". Pimenta (2006) defende que é preciso ampliar a concepção de estágio, não apenas como a teoria posta em prática, mas como um momento de pesquisa: “[...]na possibilidade de os estagiários desenvolverem postura e habilidades de pesquisador a partir das situações de estágio, elaborando projetos que lhes permitam ao mesmo tempo compreender e problematizar as situações que observam (p. 14)".

Especificamente sobre estágio supervisionado Braga (2009, p. 5) afirma ser o "momento de solidificação de conhecimento em diversas áreas que compõem a formação teórica inicial, em que o aluno é treinado, em situações reais”. Almeida (2018) reforça essa ideia ao afirmar que o estágio aproxima o acadêmico da realidade escolar. Sousa (2017) considera ser este um importante momento de formação, de desvelamento dos desafios e a (re)construção de saberes:

[...] reconhecemos o Estágio como momento privilegiado de nossa formação, pelo contato que nos proporciona com o ambiente real de trabalho, contribuindo para a aquisição e apreensão de conhecimentos inerentes à profissão docente, sobretudo, em relação ao enfrentamento dos desafios que se apresentam no cotidiano dos espaços escolares. Outra valiosa contribuição do trabalho foi a ressignificação de saberes práticos e teóricos (SOUSA, 2017, p.16).

Em concordância com os autores citados acima Braga (2009) acrescenta ainda que o estágio é um momento de alicerçar conhecimentos além de contribuir para o desenvolvimento de “[...] algumas habilidades específicas, necessárias ao seu futuro desempenho, resultando em 
fonte de crescimento e desenvolvimento pessoal e profissional (BRAGA, 2009, p. 5)". Field's (2014) ressalta a necessidade de investimento no estágio que tem uma ligação intrínseca entre a experiência e a identidade docente: “[...] como lugar de produção do saber, valorizando as experiências e as trajetórias desse percurso (p. 45)"”.

Basso (2015) defende a importância de uma reformulação curricular de forma que o estágio não fique isolado no final do curso, mas perpasse todas as disciplinas do currículo. Brabo (2015) afirma ser urgente pensar na reestruturação dos cursos de formação inicial de ensino superior de forma que os futuros professores adquiram conceitos relacionados à Educação Inclusiva. Discutir o estágio supervisionado levanta vários aspectos como podem ser ilustrados na Figura 1 abaixo, relacionando-o à pesquisa, formação, construção de saberes, bem como a relação entre teoria e prática.

Figura 1 - Nuvem de palavras sobre Estágio Supervisionado

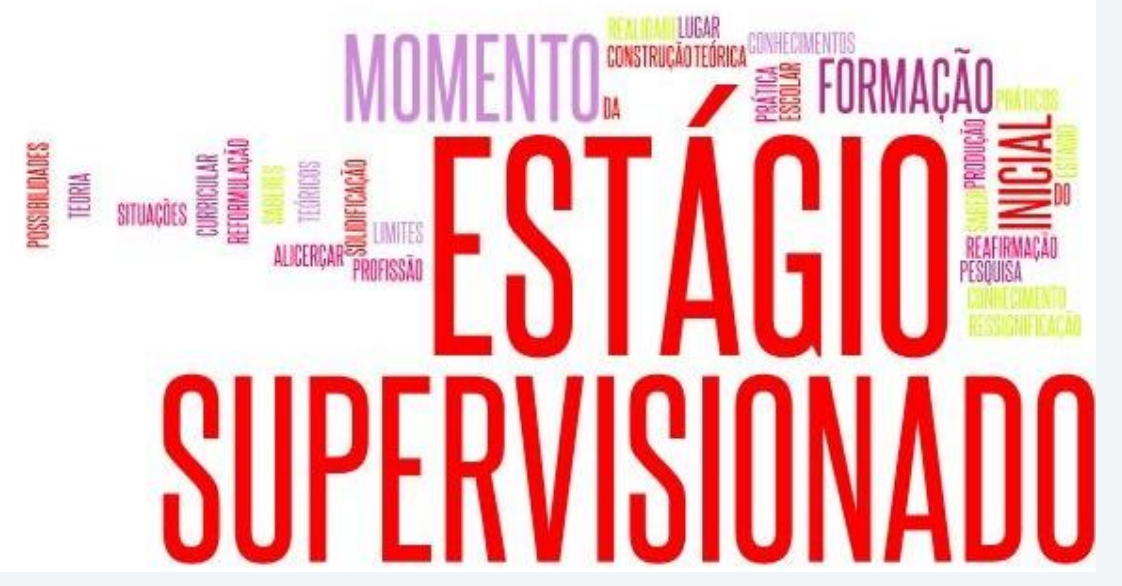

Fonte: Elaborado pelas autoras sobre concepção de estágio supervisionado adotada nas pesquisas, 2019.

Passaremos a discorrer sobre a interlocução entre o estágio e a educação inclusiva. Brabo (2015) traz um breve histórico sobre formação docente com ênfase na perspectiva inclusiva em nosso país, afirmando que deu início a partir das diretrizes da Política Nacional de Educação Especial, em 1994, ao estabelecer estágios em educação especial, na grade curricular dos cursos de formação de magistério, bem como em todos os cursos superiores. Nesse mesmo ano emerge a Declaração de Salamanca que se configurou em um marco na educação de alunos com necessidades educacionais especiais.

Toda essa conjuntura encontrou subsídios nos movimentos sociais que lutaram contra o preconceito, a discriminação, a homogeneização e a favor da cidadania, reclamando os 
direitos a todos os sujeitos, e a educação estava também em pauta. Agapito; Ribeiro (2015) refletem que esse movimento educacional inclusivo, trouxe consigo proposições políticoeducacionais de forma a adequar a formação inicial docente para modelos que reconhecessem a importância em preparar os futuros professores para trabalhar com alunos de todos os grupos sociais.

Almeida (2018) aborda em sua dissertação sobre a trajetória histórica da formação de professores para atuar na área da Educação Especial em nosso país. Afirma que a mesma foi marcada por uma série de mudanças, idas e vindas, envolvendo os dispositivos legais em discussão no Brasil desde a década de 1950 até os dias atuais, sempre com o enfoque de que a educação seja de qualidade para que todos tenham as mesmas condições e oportunidades de aprendizado.

Kauss; Reis (2013) reconhecem que a Educação Inclusiva é "viável e positiva", contudo afirmam que: " não pode ser pensada sem se considerar a estrutura social em que está inserida e pressupõe medidas transformadoras que necessitam, essencialmente, da formação consciente do profissional professor (p. 6)." Rosa (2016) através de uma discussão emblemática dos conceitos defendidos pelo paradigma da inclusão, percebendo-a como um poderoso discurso político, aborda que não basta apenas afirmar que ela é necessária para todos, precisa também mobilizar, sensibilizar e instrumentalizar a escola, professores e sociedade para garantir esse projeto.

Sousa (2017) problematiza a Educação Inclusiva no Ensino Superior, ressaltando que o princípio inclusivo precisa atender a todos os níveis e modalidades de ensino. Com o objetivo de analisar os limites e possibilidades do Estágio Supervisionado no processo de formação docente, investigou os diferentes olhares de professores com relação aos alunos com deficiência nos cursos de licenciatura, e enfatiza que: “Os cursos de licenciatura devem promover aos estudantes com deficiência uma formação que considere a sua maneira de ser e de viver no mundo. Isto, porém, não quer dizer que deixem de ser feitas intervenções cabíveis para validar esse processo formativo (SOUSA, 2017, p.105)."

Basso (2015) e Fields (2014) discutem os novos desafios que a Educação Inclusiva trouxe para os professores, especificamente aos professores das Ciências. Analisam a formação inicial dos professores, e que o desafio é por uma didática inclusiva que oportunize a construção do conhecimento científico a todos.

Os trabalhos acadêmicos-científicos analisados aqui e que fazem parte de dois importantes repositórios, apontam para mudanças necessárias na educação contemporânea. 
Contemplamos que é preciso discutir a formação ofertada aos novos docentes, tanto na questão teórica quanto prática, para que esses sujeitos ao ingressarem na docência, nos mais variados níveis e modalidades, saibam como atuar em mundo em constante mutação.

As reflexões acerca das questões didático-metodológicas não podem ficar restrita apenas no curso de Pedagogia, nas mais variadas licenciaturas precisa existir estudos que embasem os novos docentes. E os trabalhos desenvolvidos nas áreas de Ciências e Educação Física que analisamos já apontam para essa necessidade.

A educação inclusiva não pode ser vista como modismo, mas sim como uma nova forma de enxergar o mundo, de ver os (di)versos sujeitos que chegam a nossa escola e que precisam ter garantido o direito de aprender e de viver...

\section{Considerações finais}

Neste estudo analisamos a formação docente, ressaltando alguns olhares sobre a formação inicial dos professores e a educação inclusiva por meio do mapeamento e discussões dos trabalhos acadêmico-científicos, além de refletirmos as contribuições e desafios do estágio supervisionado como viés de uma proposta consolidada pelas universidades que busca uma escola democrática e plural.

Por meio de seu o objetivo central, a pesquisa pode mapear e discutir as contribuições dos trabalhos acadêmico-científicos que abordem a inter-relação entre o estágio supervisionado e educação inclusiva, despertando uma reflexão de qual tipo de escola estamos formando.

Entendemos que a escola se constituindo como espaço de formação encontra muitos problemas a serem enfrentados. Surgem aqui alguns desafios: Como a formação inicial poderá contemplar as demandas instituídas no ambiente escolar? Como atender as necessidades dos níveis e modalidades de ensino? Nesta reflexão, adentramos no questionamento: Como o estágio supervisionado vem fortalecendo a prática pedagógica inclusiva?

Com a análise dos resultados constatamos que a discussão permeia o campo do currículo, pois, precisamos ter clareza de quais práticas curriculantes estão transitando na escola para pensarmos em uma proposta de formação inicial que tente responder às referidas reflexões. Adotamos para esta pesquisa a compreensão de que o currículo não é somente uma questão de conhecimentos, mas, sobretudo, de identidade e poder.

Quando elegemos os conhecimentos e saberes considerados importantes para compor o currículo devemos nos indagar qual tipo de homem, de sociedade, de escola queremos formar. 
Que conhecimentos, saberes e atividades passam a ser importante para o estagiário tornar-se um profissional preparado a enfrentar os desafios de uma educação inclusiva. Qual currículo reconhece a presença do negro, do índio, do trabalhador, do desempregado, das mulheres, dos jovens, dos idosos, dos migrantes, da dona de casa, do deficiente físico, auditivo, visual, intelectual etc., das pessoas marginalizadas da sociedade. As respostas para estas questões devem levar à construção de um currículo que se comprometa com uma educação cidadã.

A questão problema da pesquisa: Quais são as contribuições dos trabalhos acadêmicos (2008-2018), para a produção de conhecimento na inter-relação entre estágio supervisionado e Educação inclusiva? Foi respondida ao apontarmos no estudo que só há viabilidade de formação inicial quando o designer pedagógico das instituições superiores for construído a partir das demandas pedagógicas, reflexão e ressignificação das práticas dos estagiários por meio de uma estrutura formativa, tendo como princípio a práxis dialógica e transformadora.

Diante do exposto, o conhecimento acadêmico não pode ser experienciado, produzido e acessado se não com o intuito de difundir "saberes formativo pedagógico experienciais" e promover práticas pedagógicas mais significativas, dinâmicas, reflexivas, interacionistas e, sobretudo, inclusivas.

\section{REFERÊNCIAS}

AGAPITO, Juliano; RIBEIRO, Sonia Maria. A formação inicial de professores em interlocução com a perspectiva educacional inclusiva. REUNIÃO ANUAL DA ANPED, 37. Florianópolis, 2015. Anais, 2015... Disponível em: http://www.anped.org.br/sites/default/files/trabalho-gt08-4110.pdf. Acesso em 19. ago.2019

ANDRADE, Rosana Cássia Rodrigues; RESENDE, Marilene Ribeiro. Aspectos legais do estágio na formação de professores: uma retrospectiva histórica. Educação em Perspectiva, Viçosa, v. 1, n. 2, p. 230-252, jul./dez. 2010

ANDRÉ, Marli. A produção acadêmica sobre formação de professores: um estudo comparativo das dissertações e teses defendidas nos anos 1990 e 2000. Revista Brasileira de Pesquisa sobre Formação Docente. Belo Horizonte, v. 01, n. 01, p. 41- 56, ago./dez. 2009.

ALMEIDA, Luiz Fernando Garcia de. Formação inicial do professor de Educação Física para o trabalho com alunos com necessidades educacionais especiais (Dissertação de Mestrado). Cascavel-Paraná: UNIOESTE, 2018. Disponível em <http://bdtd.ibict.br/vufind/Record/UNIOESTE-1_90efa74e54ea139b355a3838ea57e73c> Acesso em: 10 set. 2019 
BONFANTE, Juliana Gaspar Colombo; BETT, Monica Bez Batti; BITTENCOURT, Ricardo Luiz de. Revista Interna de Formação de Professores (RIFP), Itapetininga, v. 3, n.3, p. 7993, jul./set., 2018

BRABO, Gabriela Maria Babosa. A formação docente inicial na perspectiva da educação inclusiva: com a palavra, o professor formador. REUNIÃO ANUAL DA ANPED, 37. Florianópolis, 2015. Anais, 2015. Disponível em: http://www.anped.org.br/sites/default/files/trabalho-gt15-4552.pdf. Acesso em 19. ago.2019

BRAGA, Denise Rodinski. Formação inicial de professores e educação especial. REUNIÃO ANUAL DA ANPED, 32. Caxambu 2009. Anais 2009. Disponível em: http://www.anped.org.br/sites/default/files/gt08-5205-int.pdf. Acesso em 14. Ago.2019

BRASIL. Parecer CFE n. ${ }^{\circ}$ 292/62, de 14 de novembro de 1962. Fixa matérias de formação pedagógica. Disponível em <http://portal.mec.gov.br/index. php?option=com_content $\&$ view $=$ article $\& i d=12636 \&$ Itemid $=86>$. Acesso em: 19 mar 2020.

BRASIL. Ministério da Educação. Secretaria de Educação Especial. Política Nacional de Educação Especial na Perspectiva da Educação Inclusiva. Brasília: DF, 2008. Disponível em: 〈http://portal.mec.gov.br/arquivos/pdf/politicaeducespecial.pdf >. Acesso em 25 abr. 2019

BRASIL. Resolução CNE/CP 01/2002, de 18 de fevereiro de 2002. Diretrizes Curriculares Nacionais para a Formação de Professores da Educação Básica, em nível superior, em cursos de licenciatura de graduação plena. Disponível em: <http://portal.mec.gov.br/index. php?option=com_content\&view=arti cle $\&$ id $=12633 \&$ Itemid=86> . Acesso em 19 mar. 2020

BRASIL. Lei n. ${ }^{\circ}$ 9.394, de 20 de dezembro de 1996. Estabelece as diretrizes e bases da educação nacional. Disponível em: <http://www.planalto.gov.br/ ccivil_03/LEIS/ 19394.htm>. Acesso em 19 mar. 2020

BRASIL. Lei $\mathbf{n}^{\mathbf{0}} \mathbf{. 1 1 . 7 8 8}$, de 25 de agosto de 2008. Dispõe sobre o estágio de estudantes. Disponível em: <http://www.planalto.gov.br/ccivil_03/_Ato20072010/2008/Lei/L11788.htm>. Acesso em 19 mar. 2020

BRUMATI, Josimara Dias. A contribuição da Biblioteca Digital de Teses e Dissertações na disseminação do conhecimento nas áreas de Humanas e Sociais. Revista Brasileira de Biblioteconomia e Documentação. São Paulo, v.11, n. 1, p. -77, jul./dez. 2015.

BRZEZINSKI, Iria. GT8: a pesquisa sobre formação de profissionais da educação em 25 anos de história. REUNIÃO ANUAL DA ANPED, 30. Caxambu 2007. Anais 2007. Disponível em: http://www.anped.org.br/sites/default/files/trabalho_encomendado_gt08__int.pdf. Acesso em 10.set.2019

BASSO, Sabrina Pereira Soares. Cursos de Licenciatura na área de Ciências: A temática inclusão escolar de alunos com necessidades educacionais especiais (Tese). São Paulo Universidade Estadual Paulista, 2015. Disponível em 
$<$ http://bdtd.ibict.br/vufind/Record/UNSP_5759a79a88fe5327e7d43934cc35936a $>$ Acesso em: 10 set. 2019

FERREIRA, Júlio Romero; BUENO, José Geraldo Silveira. Os 20 anos do GT Educação Especial: gênese trajetória e concolidação. Revista Brasileira Educação Especial, Marília, v. 17, p. 143-170, Maio-Ago, 2011. Edição Especial.

FERREIRA, Norma Sandra de Almeida. As pesquisas denominadas "estado da arte". Educação \& Sociedade, São Paulo, ano 23, n. 79, p.257-272, ago. 2002.

FIELD'S, Karla Amâncio Pinto. Saberes profissionais para o exercício da docência em Química voltado à Educação Inclusiva. (Tese). Universidade Federal de Goiás: Goiânia, 2014. Disponível em

http://bdtd.ibict.br/vufind/Record/UFG_0ff9938e46ae61fb02e0fd80ad84c2f9> Acesso em: 10 set. 2019

FREIRE, Paulo. Pedagogia da autonomia: saberes necessários à prática educativa. São Paulo: Paz e Terra, 2000

KAUSS, Clarissa Teixeira; REIS, Haydéa Maria Marino de Sant'Anna. O profissional professor e a educação inclusiva: representações sociais em construção. REUNIÃO ANUAL DA ANPED, 36. Caxambu 2013. Anais 2013. Disponível em:

http://www.anped.org.br/sites/default/files/gt08_2785_texto.pdf. Acesso em 10. ago.2019

MARQUES, Amanda Cristina Teagno Lopes; PIMENTA, Selma Garrido. Revista

Metalinguagens, São Paulo n. 3, mai.2015, p. 135-156

PIMENTA, Selma Garrido. LIMA, Maria Socorro Lucena. Estágio e docência: diferentes concepções. Revista Poíesis: UNISUL, Volume 3, Números 3 e 4, pp.5-24, 2005/2006

ROSA, Denise Ferreira da. Produção do sujeito deficiente no contorno das políticas de educação inclusiva e da formação de professores em educação especial. (Dissertação de Mestrado). Santa Maria - RS: Universidade Federal de Santa Maria, 2016. Disponível em <https://repositorio.ufsm.br/handle/1/7278> Acesso em: 10 set. 2019

SCALABRIN, Isabel Cristina; MOLINARI, Adriana Maria Corder. A importância da Prática do Estágio Supervisionado nas Licenciaturas. Revista Científica do Centro Universitário de Araras: São Paulo, Volume 7, Número 1, 2013

SOARES, Magda. Alfabetização no Brasil: O Estado do Conhecimento. Brasília: INEP/MEC, 1989.

SOUSA, Manoel Pinéo de. O estágio curricular supervisionado nos cursos de licenciatura em tempos de inclusão. (Dissertação de Mestrado). Fortaleza: Universidade Estadual do Ceará, 2017. Disponível em <http://bdtd.ibict.br/vufind/Record/UECE-

0_1cef27c85a12946929b1f1bb6b2024028> Acesso em: 10 set. 2019 


\section{SOBRE AS AUTORAS:}

\section{Patrícia Carla da Hora Correia}

Doutora em Educação pela Universidade Federal da Bahia (UFBA). Professora da Universidade do Estado da Bahia (1994), atuando no curso de Graduação de Pedagogia e no Programa de Pós-graduação Profissional em Educação de Jovens e Adultos (MPEJA). É Coordenadora do grupo de Pesquisa Programa de Educação Inclusiva - PROGEI, faz parte do Grupo de Pesquisa Educação Inclusiva e Necessidades Educacionais Especiais GEINE da Universidade Federal da Bahia - UFBA e do grupo Educação, Etnicidade e Desenvolvimento Regional da Universidade do Estado da Bahia - UNEB, coordenando a linha de pesquisa Etnias, Educação e Inclusão Compreensiva, desenvolvendo pesquisa na área de Deficiências físicas e sensoriais nas comunidades Indígenas do Estado da Bahia e Fulni-ó em Águas Belas Pernambuco. Tem experiência na área de Educação, atuando como consultora nas áreas de planejamento, didática, políticas públicas com ênfase em Educação Especial, atuando principalmente nos seguintes temas: educação especial, educação indígena, prática pedagógica, currículo e educação inclusiva, políticas públicas nos diversos níveis e modalidades de ensino. Blog acadêmico: http://progeiuneb.blogspot.com.br/ e Site Acadêmico: www.inclusaodahora.com.br. Contato: patricia@inclusaodahora.com.br

\section{http://orcid.org/0000-0001-8041-1827}

\section{Julimar Santiago Rocha}

Mestre em Educação pela UNEB - Mestrado Profissional em Educação de Jovens e Adultos (2018). Especialista em Educação, Pobreza e Desigualdade social (UFBA). Especialista em Gestão Escolar (UFBA). Participante dos Grupos de Pesquisa: Gestão, Organização, Tecnologia e Políticas Públicas em Educação (GP-GEPE); Gestão de experiências formativas e dos saberes pedagógicos/comunicacionais do(a) professor(a) do Curso de Licenciaturas da UNEB/UESB. Professora bolsista no Curso de Pedagogia UNEAD/UNEB na orientação de TCC. Professora colaboradora em Curso de Especialização em Libras - UNIVASF. Professora bolsista no Curso de Alfabetização e Letramento - UFBA na orientação de TCC. Atuação como gestora escolar na Modalidade EJA, e professora da Educação Básica pela Secretaria Municipal de Educação de Salvador. Tem experiência na área de Educação, atuando nos seguintes temas: gestão escolar, EJA, inclusão e formação de professores. Contato: rocha.juli12@ hotmail.com (iD http://orcid.org/0000-0003-2659-0400

\section{Débora Regina Oliveira Santos}

Mestra em Educação de Jovens e Adultos pela Universidade do Estado da Bahia UNEB), especialista em Coordenação Pedagógica (UFBA), Mídias em Educação (UESB) e Metodologia do Ensino Superior (FACE). Licenciada em Pedagogia, habilitação em Formação Pedagógica e Gestão Educacional (FACE). Coordenadora Pedagógica na Rede Municipal de Gandu. Experiência profissional em gestão escolar, professora formadora do Programa de Capacitação de Gestores Escolares, presidente do Conselho Municipal de Educação, professora da educação básica, consultora pedagógica. Integrante do Grupo de Pesquisa: Gestão, organização, tecnologia e políticas públicas em educação (GP-GEPE). Pesquisadora em Educação de Jovens e Adultos, formação docente e Tecnologias de Informação e Comunicação. Contato: deborareginaos@ hotmail.com

(iD) http://orcid.org/0000-0002-0601-6789

Recebido em: 03 de abril de 2020

Aprovado em: 31 de julho de 2020 Publicado em: 07 de setembro de 2020 